\title{
Knowledge of Infertility Among Infertile Women in Bauchi, Northern Nigeria
}

\author{
Lamaran Dattijo ${ }^{1 *}$, Natasha Andreadis ${ }^{2}$, Baffah Aminu' ${ }^{1}$, Nasir Umar ${ }^{3}$, Kirsten Black²
}

\begin{abstract}
Objectives: To evaluate the knowledge, perception and treatment seeking behaviour of infertile women in Bauchi, northern Nigeria. Materials and Methods: Four hundred and six infertile women were surveyed in two hospitals using a structured questionnaire between July 2013 and June 2014.

Results: The ages of the respondents ranged from 19 to 42 years with a mean age of 30.5 years (SD: \pm 5 years). Many ( $81 \%)$ of the respondents had poor knowledge of risk factors for infertility and over $80 \%$ believed in supernatural causes. The women who had secondary level of education or higher (4.78, CI: 2.35-9.71, $P<0.001)$ and those who were employed (3.08, CI: 1.44-6.58, $P=0.04)$ had significantly better knowledge compared to those who had lower level of education and were unemployed. Almost three-quarters $(n=299,73.6 \%)$ believed that women bear the blame for infertility and $40.4 \%$ see it as a reason for the man to take another wife. Half of the women felt the woman alone should seek for treatment and only $28 \%$ reported hospital as their site of initial treatment. Most ( $\mathrm{n}=370,91 \%)$ felt infertility should be given priority in public hospitals and 308 (76\%) believed the government should pay for infertility services as done for other reproductive health $(\mathrm{RH})$ services.

Conclusion: There is low level of knowledge of infertility among infertile women in Bauchi and women bear the blame for infertility. There is need for initiatives to improve RH education in Bauchi.

Keywords: Infertility, Knowledge, Nigeria, Women
\end{abstract}

\section{Introduction}

Infertility has always existed but is now recognised as a global reproductive health $(\mathrm{RH})$ problem and as an important component of RH (1). It is a world-wide health concern and affects between $8 \%$ and $15 \%$ of couples (2). In sub-Saharan Africa, the burden of infertility is higher and is as high as $30 \%$ in some countries (3). The desire to bear children is almost a universal one in Nigeria and most parts of sub-Saharan Africa. While infertility is not a life-threatening condition, its negative social and mental impact on individuals has been documented. It is mainly women who suffer adverse effects including stigmatisation, domestic violence (4) and feelings of low self-esteem $(5,6)$. Previous studies have shown a low level of knowledge of causes of infertility in many countries in Africa despite the high prevalence of the condition $(5,7)$.

There is no data on knowledge of this important reproductive morbidity in Bauchi, Northern Nigeria. Therefore, the aim of this study is to fill the data gap by assessing the knowledge, attitude of infertility and treatment seeking behaviour among infertile women. The information will be useful in formulating interventions to improve education on reproduction.

\section{Materials and Methods}

The study was a cross-sectional survey of 406 infertile women attending the gynaecological clinics of ATBU Teaching Hospital and Federal Medical Centre, Azare, in Bauchi state, northern Nigeria.

We designed a questionnaire with questions covering socio-demographic characteristics, knowledge and perceptions of the causes and treatments of infertility and treatment seeking behaviour in relation to the presenting problem of infertility. The questionnaire was interviewer-administered and was based on one used in a study to examine infertility in Pakistan (8).

The questionnaire listed the common causes and risk factors for infertility (18 in number for both women and men). Given that belief in supernatural causes is common in these northern Nigerian communities, we also included it in the list of possible responses. We designed the questionnaire such that the participant was asked to firstly list the causes she knew, before the interviewer listed a number of causes to see if they recognised the factor as a cause of infertility or not. We thus graded the responses as "spontaneously mentioned," "recognised after the interviewer said it" or "not recognised at all as a cause of infertility." There were 20 items and an appropriate response for each item was coded 1 when it was spontaneous, 2 when it was recognised after prompting and 3 if not recognised. We added the codes for the answers to all the questions for each participant. Those with a sum between 20 and 40 were

Received 20 January 2016, Accepted 24 May 2016, Available online 14 June 2016

${ }^{1}$ Department of Obstetrics \& Gynaecology, Abubakar Tafawa Balewa University Teaching Hospital, Bauchi, Nigeria. ${ }^{2}$ Department of Obstetrics \& Gynaecology, University of Sydney, New South Wales, Australia. ${ }^{3}$ Department of Obstetrics \& Gynaecology, Federal Medical Centre, Azare, Nigeria.

*Corresponding author: Lamaran Dattijo, Department of Obstetrics \& Gynecology, Abubakar Tafawa Balewa University Teaching Hospital, Bauchi, Nigeria. Tel: +2348036301549; Email: lamaran2@yahoo.com 
deemed to have good knowledge, while those with sums between 41 and 60 defined as having poor knowledge. The questionnaire also explored society's responses to infertility and asked about acceptable or common responses to infertility such as divorce, polygamy and the attribution of blame. The study also asked participants' knowledge of available treatment options and what services existed for infertility management.

Data was analysed using SPSS (version 20, IBM, USA). Descriptive statistics were employed where appropriate to illustrate the characteristics of the studied population. Chi-square test was used to test association of the variables with knowledge. Those variables that were significant were then entered into multiple regression model to determine the strength of association. A significance level of 0.05 was used.

\section{Results}

We enrolled 406 infertile women out of the total 427 (95\%) that were approached to participate. The ages of the respondents ranged from 19 to 42 years with a mean age of 30.5 years (SD: \pm 5 years). Over $80 \%$ of the respondents were aged 35 years and below. The age distribution and other characteristics of the participants are shown in Table 1.

Just under two-thirds of participants 250 (61.6\%) spontaneously mentioned sexually transmitted infections (STI) when asked about causes of infertility, but only 146 ( $36 \%$ ) spontaneously mentioned irregular menstruation and even fewer (30\%) recognised it as a cause of infertility after it was mentioned. A substantial number did not recognise smoking $(n=324,79.8 \%)$, alcohol consumption $(n=328,80.8 \%)$ and diabetes mellitus $(n=331,81.5 \%)$ as risk factors for infertility. Over a third of women however spontaneously mentioned evil spirits $(\mathrm{n}=143,35.2 \%)$ and witchcraft $(n=153,37.2 \%)$ as causes of infertility. A similar pattern of responses was observed when the women were asked about causes and risk factors for infertility in men as shown in Table 2.

A total of 299 women (73.6\%) said the woman is blamed for infertility in the community, 290 (71.4\%) women felt it should not be a reason for divorce, while 146 (40.4\%) said it was a reason to marry another wife (Table 3 ).

A computation of the scores for the appropriate responses to causes/risk factors revealed that $94(23.4 \%)$ of the women had good knowledge, while 312 (76.8\%) of them had poor knowledge. We undertook a logistic regression analysis to determine the demographic factors predictive of having good knowledge. The model was statistically significant $\left(\chi^{2}=52.50, \mathrm{df}=11, P<0.001\right)$. The model explained $18.3 \%$ of the variation in knowledge and predicted $82.5 \%$ of cases. The women who had asecondary level of education or higher (4.78, CI: 2.35-9.71, $P<0.001)$ and those who were employed (3.08, CI: $1.44-6.58, P=0.004)$ were more likely to have good knowledge of the factors for infertility in the studied population compared to those with lower level of education and those who were unemployed (Table 4).

\begin{tabular}{|c|c|}
\hline Variable & Number (\%) \\
\hline \multicolumn{2}{|l|}{ Age (years) } \\
\hline$<20$ & $13(3.2)$ \\
\hline $21-25$ & $59(14.5)$ \\
\hline $26-30$ & $153(37.7)$ \\
\hline $31-35$ & $116(28.6)$ \\
\hline $36-40$ & $61(15.0)$ \\
\hline $41-45$ & $4(1.0)$ \\
\hline \multicolumn{2}{|l|}{ Occupation } \\
\hline Unemployed (Housewives) & $251(61.8)$ \\
\hline Students & $76(18.7)$ \\
\hline Skilled workers & $48(11.8)$ \\
\hline Unskilled workers & $31(7.7)$ \\
\hline \multicolumn{2}{|l|}{ Ethnicity } \\
\hline Hausa & 169 (41.6) \\
\hline Fulani & $67(16.5)$ \\
\hline Jarawa & $55(13.5)$ \\
\hline Yoruba & $39(9.6)$ \\
\hline Igbo & $37(9.1)$ \\
\hline Others & 39 (9.6) \\
\hline \multicolumn{2}{|l|}{ Religion } \\
\hline Christianity & $112(27.6)$ \\
\hline Islam & $294(72.4)$ \\
\hline \multicolumn{2}{|l|}{ Education } \\
\hline None & $15(3.7)$ \\
\hline Arabic/madrasah & $94(23.2)$ \\
\hline Primary & $87(21.4)$ \\
\hline Secondary & $129(31.8)$ \\
\hline Tertiary & $81(20.0)$ \\
\hline \multicolumn{2}{|l|}{ Place of residence } \\
\hline Rural & $102(25.1)$ \\
\hline Urban & 304 (74.9) \\
\hline \multicolumn{2}{|l|}{ Type of marital union } \\
\hline Monogamy & $263(64.8)$ \\
\hline Polygamy & $143(35.2)$ \\
\hline \multicolumn{2}{|l|}{ Number of marriages } \\
\hline Once & $333(82.0)$ \\
\hline Twice & $68(16.8)$ \\
\hline Thrice & $5(1.2)$ \\
\hline \multicolumn{2}{|l|}{ Parity } \\
\hline 0 & $193(47.5)$ \\
\hline 1 & $121(29.8)$ \\
\hline 2 & $64(15.8)$ \\
\hline 3 & $17(4.2)$ \\
\hline$>4$ & $11(2.7)$ \\
\hline
\end{tabular}

The majority of the women $(n=395,97 \%)$ viewed infertility as a disease and half of the sample $(n=204,50.2 \%)$ felt that the woman alone should seek treatment (Table 5). Only 115 (28\%) of participants reported the hospital as the first place of treatment. Awareness of treatment options like drugs and surgery was high (97\% and 66.3\%, respectively) among the respondents. Two hundred and forty-eight women $(61 \%)$ reported spending more than 50000 Naira (US\$250) and 370 (91\%) felt infertility should be given priority in public hospitals. The majority $308(76 \%)$ wanted the government to pay for infertility services like other $\mathrm{RH}$ services. 
Table 2. Responses to Causes/Risk Factors of Infertility of 406 Women

\begin{tabular}{|c|c|c|c|}
\hline Cause/risk factor & Spontaneously mentioned, n(\%) & Recognised, $n(\%)$ & Not recognised, $n(\%)$ \\
\hline STIs & $250(61.6)$ & $111(27.3)$ & $45(11.1)$ \\
\hline Abnormal menstruation & $146(36.0)$ & $124(30.5)$ & $136(33.5)$ \\
\hline Inadequate sexual activity & $94(23.2)$ & 89 (21.9) & $223(54.9)$ \\
\hline Smoking & $19(4.7)$ & $63(15.5)$ & $324(79.8)$ \\
\hline Alcohol consumption & $18(4.4)$ & $60(14.8)$ & $328(80.8)$ \\
\hline HIV/AIDS & $49(12.1)$ & $64(15.8)$ & $293(72.2)$ \\
\hline Diabetes mellitus & $22(5.4)$ & $53(13.1)$ & $331(81.5)$ \\
\hline Drugs & $55(13.5$ & $53(13.1)$ & $298(73.4)$ \\
\hline "How a person was created"a & $98(24.1)$ & $79(19.5)$ & $229(56.4)$ \\
\hline Evil spirits & $143(35.2)$ & $196(48.3)$ & $67(16.5)$ \\
\hline Witchcraft/curse & $153(37.7)$ & $198(48.8)$ & $55(13.5)$ \\
\hline \multicolumn{4}{|c|}{ Cause/risk factor in men } \\
\hline Smoking & $19(4.7)$ & $57(14.0)$ & $330(81.3)$ \\
\hline Alcohol consumption & $13(3.2)$ & $57(14.0)$ & $336(82.8)$ \\
\hline Erectile dysfunction & $174(42.9)$ & $128(31.5)$ & $104(25.6)$ \\
\hline Diabetes mellitus & $30(7.4)$ & $49(12.1)$ & $327(80.5)$ \\
\hline HIV/AIDS & $59(14.5)$ & $56(13.8)$ & $291(71.7)$ \\
\hline Pelvic surgery & $67(16.5)$ & $55(13.5)$ & $284(70.0)$ \\
\hline "How a person was created"a & $108(26.6)$ & $98(24.1)$ & $200(49.3)$ \\
\hline Evil spirits & $162(39.9)$ & $190(46.8)$ & $54(13.3)$ \\
\hline Witchcraft/curse & $155(38.2)$ & $189(46.6)$ & $62(15.3)$ \\
\hline
\end{tabular}

Abbreviation: STI, sexually transmissible infections.

a The local way of referring to genetic make-up of a person.

Table 3. Opinions on Social Consequences of Infertility of 406 Infertile Women

\begin{tabular}{lc}
\hline Social Consequence & Number (\%) \\
\hline Infertility as a reason for divorce & $52(12.8)$ \\
Yes & $290(71.4)$ \\
No & $64(15.8)$ \\
I do not know & \\
Infertility as a reason for another marriage & $164(40.4)$ \\
Yes & $193(47.5)$ \\
No & $49(12.1)$ \\
I do not know & \\
Who is the person blamed for infertility & $299(73.6)$ \\
Wife & $1(0.2)$ \\
Husband & $83(20.4)$ \\
Both & $10(2.5)$ \\
No one & $13(3.2)$ \\
I do not know &
\end{tabular}

\section{Discussion}

This study investigated the knowledge of causes and treatment seeking behaviour of infertility among infertile women attending two hospitals in Bauchi, northern Nigeria.

The results of this survey showed a low level of knowledge of infertility in the studied population of reproductive age women, with only $19.2 \%$ of the respondents having good knowledge of the causes of and risk factors for infertility. More than a third (33.5\%) of the respondents did not recognise irregular menstruation as a cause of infertility. Knowledge of STI as a cause, which was spontaneously mentioned by $61.6 \%$, was the most recognised. Although STIs are significant contributors to tubal damage and infertility in developing countries, women's knowledge in other African studies has varied. One study of wom- en attending the gynaecological clinic in Lagos showed that more than half (57.5\%) were aware of infertility as a complication of STIs. However, another study among 2000 men and women in rural Ghana revealed less than $2 \%$ of participants referred to STIs as a cause of infertility $(9,10)$. The finding from a qualitative study in South Africa similarly reported most infertile women and men had an inadequate understanding of the possible causes of infertility $(5,11)$. The differences in the findings between the studies could reflect the differing levels of education and development of the countries. In our study, the participants had low levels of education that most likely that was a key contributing factor to the very low levels of knowledge amongst the participants.

Over $80 \%$ of the respondents did not recognise other factors that can affect fertility such as smoking, alcohol consumption, HIV and diabetes mellitus. These findings are consistent with previous studies in both developed and developing countries. In a survey of Canadian childless women, only $50 \%$ were able to answer correctly 6 out of $16(37.5 \%)$ knowledge items on fertility and reproduction (12). In an Australian study of men and women who were planning to have a child, just over $40 \%$ were unaware that smoking and obesity can reduce fertility in women and two-thirds were unaware that these factors can affect male fertility (13). Therefore, in both high and low resource settings there exists a need to raise awareness about the lifestyle and health-related factors that can assist with prevention and management of infertility $(14,15)$.

Efficient delivery of care depends on a good understanding of the causes, experiences and consequences of infertility and of the cultural context in which the experiences occur. A significant finding of our study is that over 


\begin{tabular}{|c|c|c|c|c|}
\hline Variable & Univariate & $P$ Value & Multivariate Odds Ratio $(95 \% \mathrm{Cl})$ & $P$ Value \\
\hline \multicolumn{5}{|l|}{ Age } \\
\hline $19-24^{a}$ & $15 / 44(34.1)$ & 0.08 & 1 & \\
\hline $25-30$ & $46 / 179(25.7)$ & & $0.27(0.09-1.84)$ & 0.23 \\
\hline $31-35$ & 23/118 (19.5) & & $0.46(0.19-1.13)$ & 0.09 \\
\hline$\geq 36$ & 10/65 (15.4) & & $0.86(0.35-2.09)$ & 0.73 \\
\hline \multicolumn{5}{|l|}{ Education } \\
\hline At least primary a & 21/196 (10.7) & $<0.001$ & 1 & \\
\hline At least secondary & $73 / 210(34.8)$ & & $4.78(2.35-9.71)^{b}$ & $<0.001$ \\
\hline \multicolumn{5}{|l|}{ Occupation } \\
\hline Unemployed (housewives) ${ }^{a}$ & 45/251 (17.9) & 0.001 & 1 & \\
\hline Students & 19/76 (25.0) & & $1.65(0.83-3.29)$ & \\
\hline Employed & $30 / 79(38.0)$ & & $3.08(1.44-6.58)^{b}$ & 0.004 \\
\hline \multicolumn{5}{|l|}{ Place of residence } \\
\hline Rural $^{a}$ & $13 / 102(12.7)$ & 0.004 & 1 & \\
\hline Urban & $81 / 304(26.6)$ & & $1.14(0.54-2.39)$ & 0.73 \\
\hline \multicolumn{5}{|l|}{ Marital Union } \\
\hline Monogamous $^{\mathrm{a}}$ & $71 / 263(27.0)$ & 0.013 & 1 & \\
\hline Polygamous & $23 / 143(16.1)$ & & $1.01(0.53-1.92)$ & 0.97 \\
\hline \multicolumn{5}{|l|}{ Parity } \\
\hline Nulliparous ${ }^{\mathrm{a}}$ & $57 / 193(29.5)$ & 0.004 & 1 & \\
\hline Para 1 and above & $37 / 213(17.4)$ & & $0.81(0.33-1.95)$ & 0.63 \\
\hline \multicolumn{5}{|l|}{ Duration of infertility } \\
\hline $1-4$ years $^{\mathrm{a}}$ & $63 / 236(26.7)$ & 0.05 & 1 & \\
\hline 5 years and above & $31 / 170(18.2)$ & & $1.05(0.53-2.06)$ & 0.61 \\
\hline \multicolumn{5}{|l|}{ Type of infertility } \\
\hline Primary & 47/165 (30.3) & 0.01 & 1 & \\
\hline Secondary & 47/251 (18.7) & & $0.89(0.37-2.11)$ & 0.79 \\
\hline
\end{tabular}

aeference category; ${ }^{\mathrm{b}}$ Statistically significant.

Table 5. Attitude and Behaviour Regarding Infertility of 406 Infertile Women

\begin{tabular}{ll}
\hline Attitude/Behaviour & Number (\%) \\
\hline Do you see infertility as a disease? & \\
Yes & $395(97.3)$ \\
No & $2(0.5)$ \\
I do not know & $9(2.2)$ \\
Do you believe it is treatable? & \\
Yes & $382(94.1)$ \\
No & $1(0.2)$ \\
I do not know & $23(5.7)$ \\
Who is to seek for treatment? & \\
$\quad$ Wife & $204(50.2)$ \\
Husband & $5(1.2)$ \\
Couple & $197(48.5)$ \\
Where do you go first for treatment? & \\
Traditional healer & $171(42.1)$ \\
Hospital & $115(28.3)$ \\
Spiritual healer & $120(29.6)$ \\
\hline
\end{tabular}

a third of women believed in the role of supernatural beliefs/myths in the causation of infertility. More than $35.2 \%$ of the respondents said evil spirits and $37.7 \%$ said witchcraft contributed to infertility. These findings differ from those from a survey of 104 infertile and 277 fertile couples in a tertiary hospital in Saudi Arabia where 58.8\% and $67.5 \%$ of mentioned supernatural causes and magic as causes of infertility, respectively (16). Nevertheless, it is comparable to findings of the study of 447 women and men in Pakistani hospital clinics where 30\% reported supernatural causes and 38\% mentioned magic and from Uganda where just over half of women (51.3\%) believed evil spirits caused infertility $(8,17)$. These similar findings across different populations may be due to shared cultural or religious beliefs as in traditional human societies; supernatural forces and powers are considered to cause many disease conditions. The findings have implication for health care, as the people are likely to seek a solution to the perceived supernatural causes before presenting to the orthodox health system and this delay can affect their subsequent management.

Infertility is a social problem in addition to being a medical condition. In many communities across the world, cultural and religious norms expect a couple to have children as the fruits of marriage $(6,18)$ and failure to conceive can exert enormous strain on a couple leading to divorce and abandonment (19). In our study, $71.4 \%$ of women did not view infertility as a reason for divorce, but $12.8 \%$ of the women did. This is lower compared to a study of 104 infertile couples in Saudi Arabia amongst whom 38.5\% believed infertility was a reason for divorce (16). In societies, such as in northern Nigeria, where there is significant gender inequity, divorce (primarily the prerogative of the man) usually leads to loss of status and value of the women (20). Women have to move back to their parents' house, may lose the rights and privileges accorded to married women. Although infertility is not a valid reason for divorce under Islamic law (Shariah), it does occur in these 
societies for this reason.

Another consequence of infertility that is not prevalent in western society is polygamy. The practice is common in sub-Saharan Africa with recognition in cultural norms and Islamic laws. It was, therefore, not surprising that $40.4 \%$ of the respondents agreed that infertility was a valid reason to take another wife. The result is less than the 62.5\% reported in the Saudi Arabian study and less than the $57 \%$ reported in a study in Pakistan $(8,16)$. This difference may reflect the fact that our population was of mixed religious background including 27\% Christians in contrast to the Pakistani and Saudi studied samples that were all Muslims. Interestingly an in-depth interview study of 25 infertile women in Jordan found that women preferred the choice of polygamy to avoid the social stigma of divorce with the attendant consequences (21).

Studies show that women bear more of the blame for infertility compared to men (22-24). Our study confirmed this finding with $73.6 \%$ of the respondents reporting that women bear the blame for infertility and only $20.4 \%$ stating that men and women share the responsibility for the inability to conceive. Indeed men, usually report having had children with other women and rarely present themselves for investigations in sub-Saharan Africa (25). The social reaction towards a woman as the sole cause of a couples' infertility is distressing and may affect her self-esteem $(26,27)$. Men and women both experience the effects of infertility but compared to women; men uncommonly express concern about its impact on the stability of their marriage (11). The experience of abuse, divorce and polygamy, which carry more implication for women, may alter the perspective of how men and women view infertility.

Women's similar experiences of the consequences of infertility across many developing countries may indicate that the issues are not unique to a particular culture or religion. This may reflect the low status of women in these countries where the primary form of expression of femininity is via successful reproduction $(28,29)$. Formal education keeps the girl-child in school for most of the adolescent period and delays the age of marriage and assumption of responsibilities of childbearing. The adolescent period is the time when interventions can have a considerable effect on subsequent life outcomes. Therefore, education initiatives and empowerment are strategies that can improve the status of women in such societies and lessen the social impact of infertility $(30,31)$.

The majority (97.3\%) of the respondents in our study regard infertility as a disease that is treatable. In a similar study in Pakistan, only 55\% thought of infertility as a disease condition (8). We believe this is a favourable attitude because, with its acceptance as a disease state it will be easier to educate people on how and where to seek care. The desire to bear children is one of the strong human cravings and studies reveal many infertile clients are willing to do anything to resolve the problem $(5,24)$. In our study, half of the women felt that the woman should seek treatment alone while the other half felt the couple should seek treatment. The finding was different from studies in South Africa, Saudi Africa and Pakistan $(5,16,32)$ where the majority believed the couple should present for investigation and management together. However, our findings are similar to those in studies undertaken in Gambia and Ghana $(10,33)$ which found that women alone were the ones seeking care whether in orthodox or traditional medicine outlets.

The majority of our respondents (71.7\%) had sought care from traditional and spiritual healers for infertility before presenting to the hospitals. Previous studies have documented the use of these options of treatment alone or together with the hospitals in developing countries $(34,35)$. This is a reflection of their beliefs of the causes of their problems. It may also be an insight into issues of lack of access and availability of medical services in the study areas. In the study area, which has an estimated population of 5.9 million in 2013 there are only two medical centres that have clinics for couples with infertility but have no assisted reproductive technique (ART) option (36).

In our study, awareness of treatment options such as drugs and surgery was high, but less than a third had an awareness of ART. This is lower than the rate of $51.8 \%$ reported from Lagos, which is Nigeria's largest city and significantly below the $90 \%$ reported in studies from high resource settings (Belgium, France, Germany, Italy, Sweden, USA and Australia) $(37,38)$. ART is an advanced and effective treatment option, but it has limited availability in most of sub-Saharan Africa (39). It is only available in private health facilities found in major cities. In Nigeria, most of the private ART centres are located in Lagos $(37,40)$. It is, therefore, not surprising that most of our respondents were not aware of it.

Only $12.8 \%$ of the women were aware of adoption as a solution to infertility. In developed countries, many couples may be willing to adopt babies and some resort to international adoption due to fewer opportunities in their countries. The situation is rather different in developing countries where adoption is not common and is not seen as a solution to infertility $(41,42)$. Lack of appropriate laws on adoption and its perception as evidence of an inability to bear children limit its utilisation (43). In most Muslim societies, adoption as a solution to infertility is not an attractive option due to an emphasis on purity of family lineage and the issue of blood relationship as the basis of inheritance under Shari 'a laws (44). Public enlightenment and provision of legislation on adoption may change its perception and practice.

Healthcare requires investment in human and material resources for its sustainability. Many of the RH care services are either free or heavily subsidised in developing countries as a result of government policy and partnership with international development agencies (45). Infertility, however, does not enjoy such a privilege, and patients bear the expenses involved in its care (19). In our study, the majority of the respondents had spent more than 50000 Naira (US $\$ 250$ ) by the time they presented to the gynaecology clinic. The amount is huge in comparison to the nation- 
al monthly minimum wage of 18000 Naira (less than US\$100) (46). A substantial number of the women in our study believed the government should pay for infertility services as it does for family planning services. Studies in other developed countries have also revealed a high level of public support for reimbursement of infertility treatment (38). As part of the program to achieve universal access to RH care, governments in sub-Saharan Africa need to consider including infertility care in the $\mathrm{RH}$ package. Our study found a low level of knowledge of causes of infertility and belief in supernatural forces is common among the infertile women studied. Women bear the blame for infertility in most cases and the majority of our participants initially sought for care from traditional and spiritual healers. Infertile women want the infertility service to be a health priority of public hospitals and want the government to pay for infertility services. There is a need for initiatives to improve $\mathrm{RH}$ education in the study area. A major limitation of our study is its hospital-based nature. Although we recruited patients from the only two hospitals that offer infertility services in the area, it is still likely that those who did not seek hospital care may differ in certain ways and caution is required in extrapolating the data to all infertile women. Interviewer-bias is a possibility, but the use of a structured questionnaire and training sessions before the commencement of the study would have minimised this effect. There is also a possibility that our respondents may have provided "socially" correct answers to some of the questions, as infertility is a private matter and hardly discussed in the open. However, the clinical setting and communication about the confidentiality of the responses may have assisted the participants to disclose honest answers.

\section{Ethical Issues}

The study obtained ethical approval from the ethics committees of the two hospitals and the University of Sydney, Australia. All subjects gave an informed consent before enrolment into the study.

\section{Conflict of Interests}

We hereby declare that there is no conflict of interests

\section{Financial Support}

We appreciate the Australian Agency for International Development (AUSAID) for scholarship to undertake the study.

\section{Acknowledgments}

We acknowledged the cooperation of staff of obstetrics \& gynaecology departments of the two study sites.

\section{References}

1. Aboulghar MA. The importance of fertility treatment in the developing world. BJOG. 2005;112(9):1174-1176. doi: 10.1111/j.1471-0528.2005.00705.x.

2. Boivin J, Bunting L, Collins JA, Nygren KG. International estimates of infertility prevalence and treatment-seeking: potential need and demand for infertility medical care. Hum Reprod. 2007;22(6):1506-1512.

3. Larsen U. Infertility in central Africa. Trop Med Int Health. 2003;8:354-367.

4. Yildizhan RA, Kolusari A, Kurdoglu M, Yildizhan B, Sahin G. Domestic violence against infertile women in a Turkish setting. Int J Gynecol Obstet. 2009;104(2):110-112. doi:10.1016/j.ijgo.2008.10.007.

5. Dyer SJ. Infertility-related reproductive health knowledge and help-seeking behaviour in African countries. ESHRE Monographs. 2008;2008(1):29-33.

6. Van Balen F, Bos HM. The social and cultural consequences of being childless in poor-resource areas. Facts Views Vis Obgyn. 2009;1(2):106-121.

7. Aziken ME, Orhue AA, Kalu OO, Osemwemkha PA. Knowledge, perception and attitude of infertile women in Benin City, Nigeria to the causation of infetility and in vitro fertilisation and embryo transfer. Trop J Obstet Gynaecol. 2013; 27(2):40-45.

8. Ali S, Sophie R, Imam AM, et al. Knowledge, perceptions and myths regarding infertility among selected adult population in Pakistan: a cross-sectional study. BMC Public Health. 2011;11(1):760. doi:10.1186/1471-2458-11-760.

9. Rabiu KA, Adewunmi AA, Akinlusi FM, Akinola OI. Female reproductive tract infections: understandings and care seeking behaviour among women of reproductive age in Lagos, Nigeria. BMC Womens Health. 2010;10(1):8. doi:10.1186/1472-6874-10-8.

10. Geelhoed DW, Nayembil D, Asare K, Schagen van Leeuwen $\mathrm{JH}$, van Roosmalen J. Infertility in rural Ghana. Int J Gynaecol Obstet. 2002;79:137-142.

11. Dyer SJ, Abrahams N, Mokoena NE, Van der Spuy ZM. 'You are a man because you have children': experiences, reproductive health knowledge and treatment-seeking behaviour among men suffering from couple infertility in South Africa. Hum Reprod. 2004;19(4):960-967. doi: 10.1093/humrep/deh195.

12. Daniluk JC, Koert E, Cheung A. Childless women's knowledge of fertility and assisted human reproduction: identifying the gaps. Fertil Steril. 2012;97(2):420-426. doi: 10.1016/j.fertnstert.2011.11.046.

13. Hammarberg $K$, Setter $T$, Norman RJ, Holden CA, Michelmore J, Johnson L. Knowledge about factors that influence fertility among Australians of reproductive age: a population-based survey. Fertil Steril. 2013;99(2):502-507. doi:10.1016/j.fertnstert.2012.10.031.

14. Augood C, Duckitt K, Templeton AA. Smoking and female infertility: a systematic review and meta-analysis. Hum Reprod. 1998;13(6):1532-1539.

15. Fulford B, Bunting LE, Tsibulsky I, Boivin J. Does knowledge of fertility risks translate into action? Findings from the International Fertility Decision-Making Study (IFDMS) iStarting Familiesi. Hum Reprod. 2011;26(S1):i120-i121.

16. Abolfotouh MA, Alabdrabalnabi AA, Albacker RB, AlJughaiman UA, Hassan SN. Knowledge, attitude, and practices of infertility among Saudi couples. Int J Gen Med. 2013;6:563-573. doi:10.2147/IJGM.S46884.

17. Namujju J. Knowledge, attitudes and practices towards infertility among adults 18-40 years in Kalisizo, Rakai District in Uganda. http://makir.mak.ac.ug:8080/xmlui/ handle/10570/1705. Published 2008.

18. Sundby J. Sad not to have children, happy to be childless: a personal and professional experience of infertility. Reprod 
Health Matters. 1999;7(13):13-19. doi:10.1016/S09688080(99)90107-6.

19. Dyer SJ. The value of children in African countries: insights from studies on infertility. J Psychosom Obstet Gynaecol. 2007;28(2):69-77. doi:10.1080/01674820701409959.

20. Rouchou B. Consequences of infertility in developing countries. Perspect Public Health. 2013;133:174-179. doi:10.1177/1757913912472415.

21. Obeisat S, Gharaibeh MK, Oweis A, Gharaibeh $\mathrm{H}$. Adversities of being infertile: the experience of Jordanian women. Fertil Steril. 2012;98(2):444-449. doi:10.1016/j. fertnstert.2012.04.036.

22. Dyer S. Infertility management in Africa-setting priorities: review article. Obstetrics and Gynaecology Forum; 2002

23. Sundby J, Mboge R, Sonko S. Infertility in the Gambia: frequency and health care seeking. Soc Sci Med 1998;46(7):891-9. doi:10.1016/S0277-9536(97)00215-3.

24. Fledderjohann JJ. 'Zero is not good for me': implications of infertility in Ghana. Hum Reprod. 2012;27(5):1383-1390. doi: 10.1093/humrep/des035.

25. Dhont N, Luchters S, Ombelet W, et al. Gender differences and factors associated with treatment-seeking behaviour for infertility in Rwanda. Hum Reprod. 2010;25(8):20242030. doi:10.1093/humrep/deq161.

26. PurewalS, van den AkkerO. The socio-cultural and biological meaning of parenthood. J Psychosom Obstet Gynaecol. 2007;28(2):79-86. doi:10.1080/01674820701409918.

27. Tabong PT, Adongo PB. Understanding the social meaning of infertility and childbearing: a qualitative study of the perception of childbearing and childlessness in Northern Ghana. PloS One. 2013;8(1):e54429. doi:10.1371/journal. pone.0054429.

28. Hollos M, Whitehouse B. Women in limbo: life course consequences of infertility in a Nigerian community. Hum Fertil (Camb). 2014;17(3):188-191. doi:10.3109/14647273. 2014.936052.

29. Umeora O, Nzerem U, Eze J. What drives grand multiparous women in rural Nigeria to seek treatment for infertility. Afr J Med Health Sci. 2013;12(1):15.

30. Grown C. UN Millennium Project: Taking action: Achieving gender equality and empowering women. Task Force on Education and Gender Equality; 2005.

31. Aja-Okorie U. Women education in Nigeria: Problems and Implications for Family role and stability. Eur Sci J. 2013;9(28):272-282.

32. Sami N, Saeed Ali T. Perceptions and experiences of women in Karachi, Pakistan regarding secondary infertility: results from a community-based qualitative study. Obstet Gynecol Int. 2012;2012:108756. doi:10.1155/2012/108756.
33. Sundby J. Infertility in the Gambia: traditional and modern health care. Patient Educ Couns. 1997;31(1):29-37. doi:10.1016/S0738-3991(97)01006-9.

34. Koster-Oyekan W. Infertility among Yoruba women: Perceptions on causes, treatments and consequences. Afr J Reprod Health. 1999;3(1):13-26.

35. Hollos M, Larsen U, Obono O, Whitehouse B. The problem of infertility in high fertility populations: meanings, consequences and coping mechanisms in two Nigerian communities. Soc Sci Med. 2009;68(11):2061-2068. doi:10.1016/j.socscimed.2009.03.008.

36. UNFPA Nigeria. UNFPA in Bauchi. http://nigeria.unfpa. org/bauchi.html. Accessed 12 October 2014.

37. Fabamwo AO, Akinola OI. The understanding and acceptability of assisted reproductive technology (ART) among infertile women in urban Lagos, Nigeria. J Obstet Gynaecol. 2013;33(1):71-74. doi: 10.3109/01443615.2012.730077.

38. Adashi EY, Cohen J, Hamberger L, et al. Public perception on infertility and its treatment: an international survey. The Bertarelli Foundation Scientific Board. Hum Reprod. 2000;15(2):330-334. doi:10.1093/humrep/15.2.330.

39. Ombelet W, Campo R. Affordable IVF for developing countries. Reprod Biomed Online. 2007;15(3):257-265. doi:10.1016/S1472-6483(10)60337-9.

40. National Population Commission Nigeriad, ICF International. Nigeria Demographic and Health Survey 2013. Abuja, Nigeria and Rockville, Maryland, USA: NPC and ICF International; 2014.

41. Oladokun A, Arulogun O, Oladokun R, et al. Attitude of infertile women to child adoption in Nigeria. Niger J Physiol Sci. 2010;25:47-49.

42. Nwobodo EI, Isah YA. Knowledge, attitude and practice of child adoption among infertile female patients in Sokoto north-west Nigeria. Niger Postgrad Med J. 2011;18(4):272275.

43. Oladokun A, Arulogun O, Oladokun R, et al. Acceptability of child adoption as management option for infertility in Nigeria: Evidence from focus group discussions. Afr J Reprod Health .2009;13(1):79-91

44. Inhorn MC. "He won't be my son": Middle Eastern Muslim men's discourses of adoption and gamete donation. Med Anthropol Q. 2006;20(1):94-120.

45. van Zandvoort $\mathrm{H}$, de Koning $\mathrm{K}$, Gerrits T. Viewpoint: medical infertility care in low income countries: the case for concern in policy and practice. Trop Med Int Health. 2001;6(7): 563-569. doi:10.1046/j.1365-3156.2001.00756.x

46. National Assembly of FRoN. National Minimum Wage Amendment Act 2011. Abuja, Nigeria; 2011.

Copyright (C) 2016 The Author(s); This is an open-access article distributed under the terms of the Creative Commons Attribution License (http://creativecommons.org/licenses/by/4.0), which permits unrestricted use, distribution, and reproduction in any medium, provided the original work is properly cited. 